\title{
Steroid receptor RNA activator inhibits the migration, invasion and stemness characteristics of renal cell carcinoma cells
}

\author{
CHANJUAN ZHANG ${ }^{1,2^{*}}$, NENG ZHU ${ }^{3 *}$, CHAN LIU $^{1,2^{*}}$, HONGTAO WU ${ }^{4}$, \\ YANTAO YIN $^{1,2}$, YANING SHI ${ }^{1,2}$, DUANFANG LIAO ${ }^{1,2}$ and LI QIN ${ }^{1,2}$ \\ ${ }^{1}$ School of Pharmacy, ${ }^{2}$ Division of Stem Cell Regulation and Application, Hunan University of Chinese Medicine;
${ }^{3}$ Department of Urology, The First Hospital of Hunan University of Chinese Medicine, Changsha, Hunan 410208;
${ }^{4}$ Department of Urology, The Second Xiangya Hospital of Central South University, Changsha, Hunan 410011, P.R. China
}

Received March 19, 2020; Accepted August 28, 2020

DOI: $10.3892 /$ ijmm.2020.4730

\begin{abstract}
Renal cell carcinoma (RCC) has a high mortality rate among urological malignancies, and its underlying mechanisms remain unclear. Steroid receptor RNA coactivator (SRA) belongs to the long non-coding RNAs (lncRNAs) and has been demonstrated to be closely related to various types of cancer. In the present study, the decreased expression level of SRA was first confirmed in RCC tissues and cell lines by RT-qPCR. Using knockdown or overexpression systems, it was then found that SRA inhibited the proliferation of RCC cell lines and promoted their apoptosis. In addition, SRA suppressed the migration and invasion, and altered EMT-related markers in RCC cells. More importantly, it was demonstrated that SRA reduced percentage of $\mathrm{CD} 44^{+} / \mathrm{CD} 24^{-}$cells and the sphere-forming efficiency. SRA also attenuated the expression levels of CD44, SOX-2, ABCG2 and OCT-4, which are all associated with cancer cell stemness characteristics. Although SRA increased the phosphorylation of extracellular-regulated protein kinase (ERK), the ERK1/2 pathway could not further interfere with the alteration of EMT-related markers mediated by SRA. Notably, the ERK inhibitor, PD98059, abolished ERK1/2 phosphorylation, whereas it did not exert any marked effects on cell proliferation and EMT-related markers mediated by SRA. Taken together, the findings of the present study indicate that SRA is an important molecule that inhibits the migration, invasion and stem cell characteristics of RCC cells; the ERK signaling pathway may not be involved in this process.
\end{abstract}

Correspondence to: Professor Li Qin, School of Pharmacy, Hunan University of Chinese Medicine, 300 Xueshi Road, Hanpu Science and Education District, Changsha, Hunan 410208, P.R. China E-mail: lqin@hnucm.edu.cn

*Contributed equally

Key words: renal cell carcinoma, steroid receptor RNA activator, cell motility, ERK signaling pathway

\section{Introduction}

As the most commonly occurring form of primary renal tumor, renal cell carcinoma ( $\mathrm{RCC}$ ) is a malignancy accompanied by a high mortality rate, with approximately 202,000 newly diagnosed cases and 102,000-related deaths worldwide annually (1-3). Surgical resection remains the only known curative treatment for localized RCC (2). Additionally, radiotherapy and chemotherapy are considered in some cases (4). However, cancer relapse in a number of patients occurs frequently due to resistance, resulting in a $12 \%$-year survival rate for patients with metastatic disease $(5,6)$. Therefore, recurrence remains the main reason for the poor prognosis. However, the underlying mechanisms responsible for RCC recurrence have not yet been fully elucidated.

Steroid receptor RNA activator (SRA) functions as coactivator in various types of cancer, such as breast cancer $(7,8)$ ovarian and prostate cancers $(7,8)$. Compared to adjacent normal tissues, the levels of SRA have been found to be elevated in breast cancer tissues (9). Patients with breast cancer with a high SRA level have a significantly worse survival rate than patients with a low SRA level. It has been indicated that SRA may serve as a novel prognostic marker for patients with estrogen receptor (ER)-positive breast cancer (10). Moreover, SRA is a potent inducer and regulator of gene expression, particularly of genes associated with epithelial-mesenchymal transition (EMT) and the Notch signaling pathway in cervical cancer (11). Although there is limited evidence linking SRA to RCC, the immunohistochemistry (IHC) of primary RCC samples has revealed that a high androgen receptor expression is significantly associated with a lower tumor stage and a better prognosis $(12,13)$. Additionally, the expression levels of glucocorticoid and progestin receptor are increased in RCC tissues (14).

In the present study, the role and underlying mechanisms of SRA in RCC were investigated. Mechanistic analysis demonstrated that SRA suppressed the stem-like features of RCC cells. However, the ERK signaling pathway was found potentially not be involved in the SRA-induced migration and invasion of RCC cells. Taken together, SRA may be a novel and promising therapeutic target in RCC therapy. 


\section{Materials and methods}

Human tissue samples. To compare the expression levels of SRA among RCC development, RCC tissues (14 cases) and adjacent non-tumorous tissues (14 cases) were obtained. The tissues were obtained from the Department of Cancer Resource Base at Sun Yat-sen University (SYSUCC) Cancer Center 7 years ago. All the fresh specimens were stored in liquid nitrogen until use. These tissues were confirmed by doctors from the Department of Pathology, SYSUCC. All the recruited patients provided their oral informed consent prior to their inclusion. Ethical consent was granted for the study by the Committees for Ethical Review of Hunan University of Chinese Medicine. The ethics committee agreed with informed consent being obtained orally in the present study.

Cells and cell culture. RCC cell lines (786-O, SN12C, SKRC39, A498 and Caki-1), a papillary renal cell carcinoma cell line (Caki-2) and the HK-2 cell line were obtained from SYSUCC. The RCC and Caki-2 cells were cultured in RPMI-1640 (Gibco; Thermo Fisher Scientific, Inc.) and the HK-2 cells were cultured in Dulbecco's modified Eagle's medium (DMEM; Gibco; Thermo Fisher Scientific, Inc.). All cells were cultured with $10 \%$ fetal bovine serum (FBS; Gibco; Thermo Fisher Scientific, Inc.) and $1 \%$ penicillin/streptomycin (Invitrogen; Thermo Fisher Scientific, Inc.) in a $5 \% \mathrm{CO}_{2}$ humidified atmosphere at $37^{\circ} \mathrm{C}$. The short 6 tandem repeat (STR) testing was used to authenticate all cell lines and all cells were maintained mycoplasma-free. Cells were treated with $5 \mu \mathrm{M}$ PD98059 (MedChemExpress LLC) for $24 \mathrm{~h}$.

Stable knockdown of SRA in SKRC39 cells. The SKRC39 cells were divided into the following groups: The short hairpin RNA (shSRA) group and the scramble group (with the same amount of nonsense RNA). Plasmids (0.6 g) in the shRNA and scramble groups were diluted in $250 \mu \mathrm{l}$ Opti-MEM (Thermo Fisher Scientific, Inc.). Similarly, Lipofectamine 2000 (Invitrogen; Thermo Fisher Scientific, Inc.) was first diluted in $250 \mu \mathrm{l}$ Opti-MEM before being added in a dropwise matter to the plasmid solution. The mixture was incubated at $25^{\circ} \mathrm{C}$ for 20 min prior to transfection into the SKRC39 cells. The SKRC39 cells were transfected for $48 \mathrm{~h}$. The following are the target sequences of the shRNA plasmid (Guang Zhou Fu Neng) applied: Non-target shRNA sequence, 5'-GCTTCG CGCCGTAGTCTTA-3'; sequence 1 (for SKRC39-shSRA1 cells), 5'-GGAGGAAAGTTGTCAATAC-3'; sequence 2 (for SKRC39-shSRA3 cells), 5'-TCAGTGGATGGTAGGAGTT-3'.

Stable overexpression of SRA in A498 cells. Lentiviral plasmid was packaged and used for cell transfection according to the manufacturer's instructions (Invitrogen; Thermo Fisher Scientific, Inc.). The clone-A498 cells were transfected with $1 \mathrm{ng} / \mu 1 \mathrm{pLenti6} / \mathrm{V} 5-\mathrm{SR} A$ or $1 \mathrm{ng} / \mu 1 \mathrm{pLenti6/V5}$ (Invitrogen; Thermo Fisher Scientific, Inc.) using Lipofectamine 2000 (Invitrogen; Thermo Fisher Scientific, Inc.). Puromycin (Sigma-Aldrich; Merck KGaA) was added to select stably transfected clones for 21 days.

MTS assay. Cell proliferation was assessed every day of the week upon the use of 3-(4,5-dimethylthiazol-2-yl)-5-(3-carb
oxymethoxyphenyl)-2-(4-sulfophenyl)-2H tetrazolium inner salt (MTS) (Sigma-Aldrich; Merck KGaA). The optical absorbance at $490 \mathrm{~nm}$ was measured using ElX 800 microplate reader (BioTek Instruments Inc.).

Colony formation assays. Cells were seeded in 6-well plates at $50 \%$ confluence and then transfected with SRA overexpression plasmid or shSRA. AT $24 \mathrm{~h}$ post-transfection, the cells were seeded in 6-well plates and cultured for 15 days. Colonies on each plate were counted using a TH4-200 microscope (Olympus Corporation) following fixation with $4 \%$ paraformaldehyde and staining with $0.1 \%$ crystal violet (Beijing Solarbio Science \& Technology Co., Ltd.) at $25^{\circ} \mathrm{C}$ for $15 \mathrm{~min}$.

Transwell cell migration assay. Transwell chambers (Costar, Corning Inc.) coated without Matrigel (BD Biosciences) on the pore size of an $8 \mu \mathrm{m}$ membrane were used to investigate cell migration. The cells were starved for $24 \mathrm{~h}$. Following cells digested with $0.25 \%$ trypsin-EDTA (Thermo Fisher Scientific Inc.) and centrifugated at $300 \mathrm{x} \mathrm{g}$ for $5 \mathrm{~min}$ at $25^{\circ} \mathrm{C}$, the cells were resuspended in serum-free medium, and the cells were counted under CKX41 light microscope (Olympus Corporation). The cell concentration was adjusted to $2 \times 10^{4}$ cells $/ 200 \mu \mathrm{l}$, and the cell suspension was placed in the bottom of a 24 -well plate. This was followed by the addition of $800 \mu \mathrm{l}$ of $10 \%$ FBS medium to each well. Following incubation at $37^{\circ} \mathrm{C}$ for $24 \mathrm{~h}$, the cells in the internal compartment were removed using a cotton swab. The migrated cells were fixed in methanol and stained with a $1 \%$ crystal violet solution at $25^{\circ} \mathrm{C}$ for $15 \mathrm{~min}$. Under CKX41 light microscope (Olympus Corporation), 3 randomly selected fields of view at x200 magnification were counted, and images were captured using Olympus Stream system (Olympus Corporation).

Transwell cell invasion assay. Transwell invasive chambers coated with Matrigel on the upper surface of an $8 \mu \mathrm{m}$ (pore size) membrane were used to determine cell invasion. Cells were plated in new 24 -well plates, $500 \mu 1$ of serum-free medium were added to the upper and lower chambers, and a serum-free cell suspension was prepared following culture at $37^{\circ} \mathrm{C}$ for $24 \mathrm{~h}$. The cells were counted under a microscope and were then adjusted to $4 \times 10^{4}$ cells $/ 200 \mu 1$. The cells were all transferred to a new well plate, the upper chamber medium was removed, $200 \mu 1$ cell suspension was added, and the lower chamber was filled with $800 \mu \mathrm{l}$ of $10 \%$ FBS medium. Following culture at $37^{\circ} \mathrm{C}$ for $24 \mathrm{~h}$, the cells in the inner chamber were not wiped off using a cotton swab. The invasive cells were fixed and stained with $1 \%$ crystal violet solution at $25^{\circ} \mathrm{C}$ for $15 \mathrm{~min}$. Under CKX41 light microscope (Olympus Corporation), 3 fields (x200 magnification) were selected randomly for counting and photographing to compare the differences in cell invasiveness between the 2 groups.

Western blot analysis and antibodies. Cell lysates were extracted with radio-immunoprecipitation assay (RIPA, Beyotime Institute of Biotechnology, Inc.) buffer with protease inhibitor cocktail (CWBiotech). Protein concentrations were determined using the $\mathrm{BCA}^{\mathrm{TM}}$ Protein Assay kit (CWBiotech) according to the protocol provided by the manufacturer. Proteins $(20 \mu \mathrm{l})$ loaded onto each lane were subjected to $10 \%$ 
sodium dodecyl sulfate-polyacrylamide gel electrophoresis (SDS-PAGE), and then transferred to a polyvinylidene difluoride (PVDF, EMD Millipore) membrane. After blocking with $5 \%$ skimmed milk for $4 \mathrm{~h}, \mathrm{PVDF}$ membranes were incubated overnight at $4^{\circ} \mathrm{C}$ with the following primary antibodies: Cyclin D1 (1:1,000; cat. no. ab16663, Abcam), cyclin E (1:1,000; cat. no. 4129, Cell Signaling Technology, Inc.), cyclin-dependent kinase (CDK)4 (1:1,000; cat. no. 11026-1-AP), CDK6 (1:1,000; cat. no. 14052-1-AP) (both from Proteintech), poly(ADP-ribose) polymerase (PARP; 1:1,000; cat. no. 9532), cleaved-PARP $(1: 1,000$; cat. no. 5625), p53 (1:1,000; cat. no. 2527), p21 (1:1,000; cat. no. 2947), $\beta$-actin $(1: 1,000$; cat. no. 4970) (all from Cell Signaling Technology, Inc.), desmoplakin (1:1,000; cat. no. ab109445, Abcam), E-cadherin (1:1,000, cat. no. 3195), fibronectin (1:1,000; cat. no. 26836), $\mathrm{N}$-cadherin $(1: 1,000$; cat. no. 13116), Vimentin $(1: 1,000$; cat. no. 5741), Snail (1:1,000; cat. no. 3879), p-ERK1/2 (1:1,000; cat. no. 4370), ERK1/2 (1:1,000; cat. no. 4695), p-JNK (1:1,000; cat. no. 4668), JNK (1:1,000; cat. no. 9252), p-STAT3 (1:2,000, cat. no. 9145), STAT3 (1:1,000; cat. no. 30835) and GAPDH (1:1,000; cat. no. 5174) (all from Cell Signaling Technology, Inc.). After rinsing with TBST 3 times for $10 \mathrm{~min}$ each time, the PVDF membranes were incubated with anti-rabbit antibody (1:2,000; cat. no. 7074, Cell Signaling Technology, Inc.) or anti-mouse (1:2,000; cat. no. 14709, Cell Signaling Technology, Inc.) at room temperature for $1.5 \mathrm{~h}$. Subsequently, the membranes were rinsed with TBST 3 times (10 min each time) and visualized using Pierce ${ }^{\mathrm{TM}}$ ECL Western Blotting Substrate (Pierce; Thermo Fisher Scientific, Inc.) (15). The blots developed with chromogenic substrates were stripped of antibodies by using stripping buffer solutions (Beyotime Institute of Biotechnology Inc.). The blots were then re-probed to detect a second protein with the same or very similar molecular weights through chemiluminescence.

Reverse transcription-quantitative PCR (RT-qPCR). Total cellular RNA and tissue RNA were extracted using TRIzol reagent (Life Technologies; Thermo Fisher Scientific, Inc.). Total RNA was quantified using a Nanodrop 1000 spectrophotometer (Thermo Fisher Scientific, Inc.) and equal amounts $(1 \mu \mathrm{g})$ were transcribed into cDNA using the iScript ${ }^{\mathrm{TM}} \mathrm{cDNA}$ Synthesis kit (cat. no. 1708891, Bio-Rad Laboratories, Inc.) according to the manufacturer's protocol. The appropriate size of the qPCR products was confirmed by agarose gel electrophoresis. Subsequently, the samples were amplified and analyzed using a SYBR Premix Ex Taq ${ }^{\mathrm{TM}}$ kit (cat. no. RR820A; Takara Bio, Inc.) and an Applied Biosystems 7500 system (Thermo Fisher Scientific, Inc.). The thermocycling conditions were as follows: $95^{\circ} \mathrm{C}$ for $10 \mathrm{~min}$, followed by 40 cycles of $95^{\circ} \mathrm{C}$ for $30 \mathrm{sec}, 55^{\circ} \mathrm{C}$ for $30 \mathrm{sec}$ and $72^{\circ} \mathrm{C}$ for $1 \mathrm{~min}$. All PCR assays were replicated at least 3 times. The fold change in gene expression was calculated using the $2^{-\Delta \Delta \mathrm{Cq}}$ method (16). A melting curve analysis was performed for each amplicon to verify the specificity of each amplification step. $\beta$-actin was used as the normalization controls for RCC cell lines. The gene primers used for amplification are presented in Table I.

Flow cytometry. The cell cycle was analyzed with a commercial kit (Beyotime Institute of Biotechnology, Inc.) according to the manufacturer's instructions. Briefly, the cells were collected and fixed with pre-cooling $70 \%$ alcohol for $2 \mathrm{~h}$ at $4^{\circ} \mathrm{C}$. After discarding the supernatant, the precipitate was washed with PBS and centrifuged at $300 \mathrm{xg}$ for $5 \mathrm{~min}$ at $25^{\circ} \mathrm{C}$. A total of $500 \mu \mathrm{l}$ of staining buffer, including $25 \mu \mathrm{l}$ propidium iodide (PI) staining solution (Beijing Solarbio Science \& Technology Co., Ltd.), $100 \mu 1$ RNase A (Thermo Fisher Scientific, Inc.) and $0.2 \%$ Triton X-100 (Beijing Solarbio Science \& Technology Co., Ltd.) were added to the wells, followed by incubation for $30 \mathrm{~min}$ at $37^{\circ} \mathrm{C}$. The samples were then detected immediately using a flow cytometer (Beckman Coulter, Inc.) (17).

Apoptosis assays were performed with the Annexin VFITC/propidium iodide (PI) apoptosis detection kit from KeyGen Biotech according to manufacturer's instructions. RCC cells were collected and fixed in $75 \%$ ethanol overnight. The cells were subsequently incubated with $500 \mu 1$ of binding buffer, $5 \mu \mathrm{l}$ of Annexin V-FITC and $5 \mu \mathrm{l}$ propidium Iodide for $15 \mathrm{~min}$ at $25^{\circ} \mathrm{C}$ in the dark. A flow cytometer (Beckman Coulter, Inc.) and Kaluza software 2.0 (Beckman Coulter, Inc.) were used to detect and analyze the percentage of apoptotic and necrotic cells.

CD $44^{+} / \mathrm{CD} 24^{-}$cell population analysis was performed by flow cytometry. Allophycocyanin (APC)-conjugated mouse anti-human CD44 monoclonal antibody (cat. no. BD 559942) and phycoerythrin/cyanine 7 ( $\mathrm{PE} / \mathrm{Cy} 7)$-conjugated mouse anti-human CD24 monoclonal antibody (cat. no. BD 561646) were purchased from BD Pharmingen (BD Biosciences). CD24 and CD44 expression was analyzed in cells derived from monolayer cultures following dissociation in trypsin-EDTA at $37^{\circ} \mathrm{C}$. Cells $\left(1 \times 10^{5}\right)$ were centrifuged at $300 \mathrm{x} \mathrm{g}$ for $5 \mathrm{~min}$ at $25^{\circ} \mathrm{C}$. The cells were washed in PBS, resuspended with anti-CD24-PE/Cy7 (1:20 dilution) and anti-CD44-APC (1:20 dilution). Samples were incubated for $30 \mathrm{~min}$ at $4^{\circ} \mathrm{C}$ in the dark. The labeled cells were washed using PBS and analyzed using a BD FACSAria II flow cytometer and software DiVa (BD Biosciences). The negative fraction was determined using appropriate isotype controls.

Statistical analysis. The results are expressed as the means \pm SD. A two-tailed Student's t-test was used for statistical comparisons. A paired t-test was used for patient tissue comparisons, and an unpaired t-test was used for cell line analyses. One-way analysis of variance (ANOVA) was used to analyze the significance among groups. The least significant difference (LSD) was used as a post hoc test was used following a significant one-way ANOVA result when analyzing datasets containing 3 groups. For datasets containing $>3$ groups, the results were analyzed by one-way ANOVA, followed by Tukey's post-hoc test. P-value $<0.05$ was considered to indicate a statistically significant difference.

\section{Results}

SRA is downregulated in both RCC clinical samples and cell lines. To explore the clinical significance of SRA in human RCC, RT-qPCR was applied to detect the expression of SRA in RCC tissues and adjacent tissues from 14 patients (Fig. 1A). Compared to the matched normal renal tissues, the expression levels of SRA were significantly lower in RCC tissues. To confirm this result, the expression levels of SRA were evaluated in a panel of RCC cell lines (786-O, SN12C, SKRC39, 
Table I. Sequences of primers used for RT-qPCR.

\begin{tabular}{lll}
\hline Gene name & \multicolumn{1}{c}{ Forward } & \multicolumn{1}{c}{ Reverse } \\
\hline SRA & & \\
$\beta$-actin & 5'-GGCTCTACTGGTGCAAGAGC-3' & 5'-GGAAGCCTGGT ATGGTATGG-3' \\
Snail & 5'-CATCCGCAAAGACCTGTACG-3' & 5'-CCTGCTTGCTGATCCACA TC-3' \\
E-cadherin & 5'-CCCAATCGGAAGCCTAACTA-3' & 5'-GCTGGAAGGTAAACTCTGGA-3' \\
Vimentin & 5'-CCTGGGACTCCACCTACAGA-3' & 5'-CAACATACCTGATGGGGCGG-3' \\
& 5'-GCTGAATGACCGCTTCGCCAAC-3' & 5'-GCTCCCGCATCTCCTCCTCGTA-3' \\
\hline
\end{tabular}

SRA, steroid receptor RNA coactivator.

A498, Caki-1 and Caki-2 cells) and renal tubular epithelial cells (HK-2 cells). Consistent with the results obtained with the clinical samples, the expression levels of SRA were significantly lower in the RCC cell lines than in the HK-2 cells (Fig. 1B). Furthermore, among the RCC cell lines, the SKRC39 cells, the metastatic cell line, Caki-1, and the papillary renal cell carcinoma cell line, Caki-2, exhibited higher SRA levels than non-the metastatic cell lines, 786-O, SN12C and A498 (Fig. 1B). These data suggested a potential role of SRA in the progression of RCC.

SRA inhibits the viability and proliferation of RCC cell lines. Based on the above-mentioned results, the A498 cells with a low SRA level and SKRC39 cells with a high SRA level, were used to verify the hypothesis of the role of SRA in RCC. Several cell clones with genetically manipulated SRA were obtained as follows: i) A498 cells stably overexpressing SRA (A498-SRA) and a negative control A498 (A498-NEG) (Fig. 2A); and ii) SKRC39 cells subjected to the shRNA-mediated knockdown of SRA (SKRC39-shSRA1 and SKRC39-shSRA3), and expressing non-targeting shRNA (SKRC39-NEG) (Fig. 2B). As was expected, the overexpression of SRA significantly inhibited the proliferation of the A498-SRA cells, compared with that of the A498-NEG cells (Fig. 2C, upper panel). However, the knockdown of SRA in the SKRC39 cells exerted opposite effects (Fig. 2D, upper panel). Additionally, SRA overexpression reduced the colony formation ability of the A498 cells (Fig. 2C, lower panels), while the downregulation of SRA promoted the colony formation of SKRC39 cells (Fig. 2D, lower panels).

SRA inhibits the cell cycle and promotes the apoptosis of $R C C$ cell lines. It is known that cell proliferation is a cell cycle-dependent process during cancer development (18). In the present study, to further examine the effects of SRA on RCC proliferation, a cell cycle analysis was performed using flow cytometry. A significant accumulation of A498-SRA cells in the G0/G1 phase accompanied by a reduction in the number of cells in the S phase was observed (Fig. 3A). However, SRA knockdown in the SKRC39 cells promoted cell entry into the S phase (Fig. 3B). These data indicated that SRA inhibited RCC cell proliferation possibly by inducing cell cycle arrest at the $\mathrm{G} 0 / \mathrm{G} 1$ phase. Subsequently, the expression levels of the cell cycle-related proteins were detected. Cyclin D1, CDK4, CDK6 and cyclin $\mathrm{E}$ are key proteins regulating cell cycle progression from the G1 to the S phase (19). The present study found that SRA overexpression markedly downregulated cyclin D1 and CDK4 expression, whereas it exerted no obvious effects on CDK6 and cyclin E expression (Fig. 3E). Conversely, the knockdown of SRA upregulated the levels of cyclin D1, CDK4 and CDK6 (Fig. 3E).

The anti-apoptotic ability is one of the important characteristics of tumor cells. The present study thus examined the effects of SRA on apoptosis using flow cytometry. The results revealed that the apoptotic rate of the A498 cells transfected with SRA overexpression plasmid was significantly increased compared with that of the control cells (Fig. 3C). The knockdown of SRA markedly reduced the percentage of apoptotic cells (Fig. 3D). PARP1 is involved in the initial response to DNA damage, which is also inactivated by caspase- 3 cleavage in p53-dependent manner (20). In the present study, the overexpression of SRA markedly increased the cleavage of PARP in the A498 cells, while it also increased the levels of p53 and p21 (Fig. 3F). The knockdown of SRA exerted opposite effects on the SKRC39 cells (Fig. 3F). Thus, SRA inhibited RCC cell proliferation by interfering with cell cycle progression and promoting cell apoptosis.

SRA inhibits the migration, invasion and EMT of RCC cells. To examine the effects of SRA on cell motility, Transwell assay was performed. It was found that the stable overexpression of SRA significantly inhibited the migration and invasion of A498 cells (Fig. 4A). By contrast, the knockdown of SRA enhanced the migratory and invasive capabilities of the SKRC39 cells (Fig. 4B). During cancer migration and invasion, EMT is triggered by multiple signal pathways. Moreover, the activation of EMT further facilitates stem cell-like properties in cancers $(21,22)$. Snail, a zinc-finger transcription factor, is directly involved in the repression of epithelial marker, E-cadherin, transcription and promotes the acquisition of a mesenchymal phenotype during EMT process $(23,24)$. The findings of the present study demonstrated that the overexpression of SRA in the A498 cells resulted in an increment in the levels of epithelial markers (desmoplakin and E-cadherin), and led to a decrease in the levels of mesenchymal markers, such as fibronectin, $\mathrm{N}$-cadherin, vimentin and Snail. Conversely, the SKRC39-shSRA cells exhibited opposite effects (Fig. 4C).

$S R A$ inhibits the stem-like characteristics of RCC cells. It has been reported that cancer cell phenotype and biology of $\mathrm{CD} 44^{+} / \mathrm{CD} 24^{-}$cells are often applied to 
A

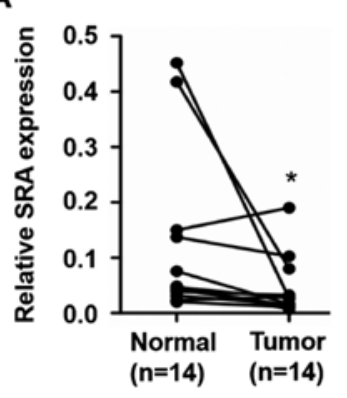

B

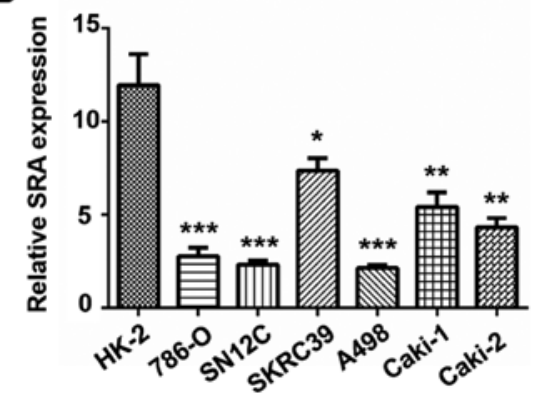

Figure 1. Expression levels of SRA are decreased in RCC tissues and cell lines. (A) The expression levels of SRA in RCC and adjacent tissues were measured by RT-qPCR. (B) The expression levels of SRA in HK-2 cells and RCC cell lines were detected by RT-qPCR assay. Data represent the means \pm SD of 3 independent experiments. ${ }^{*} \mathrm{P}<0.05,{ }^{* *} \mathrm{P}<0.01,{ }^{* * * *} \mathrm{P}<0.001$ vs. normal tissue or HK-2 cells. SRA, steroid receptor RNA coactivator; RCC, renal cell carcinoma.

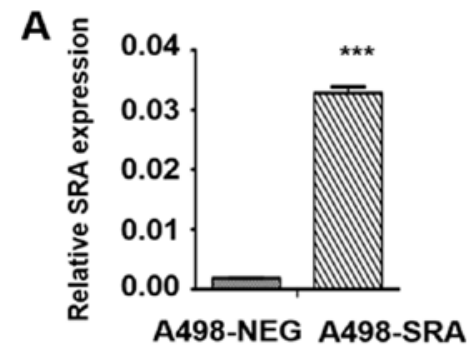

C
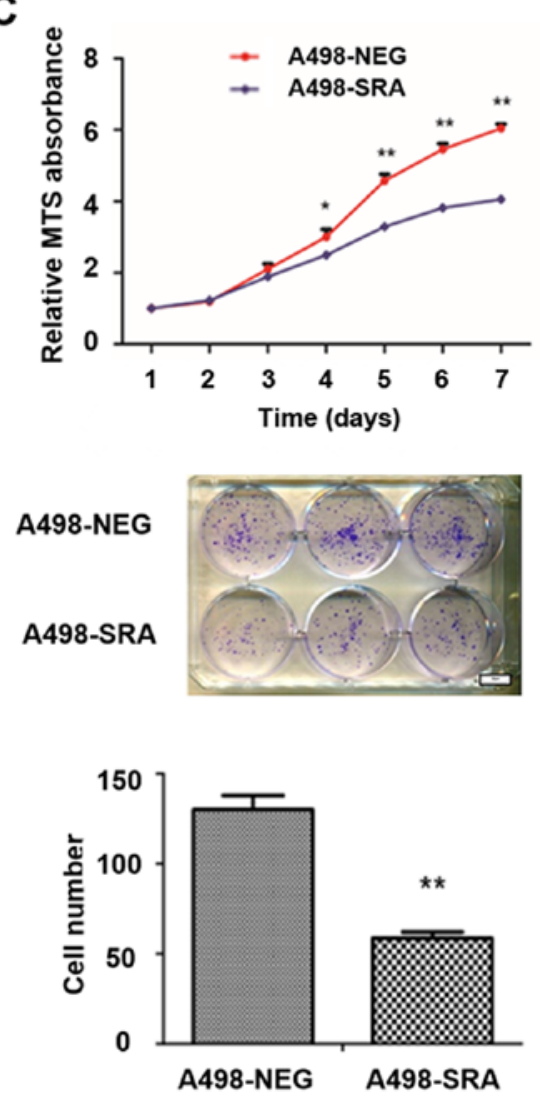

B

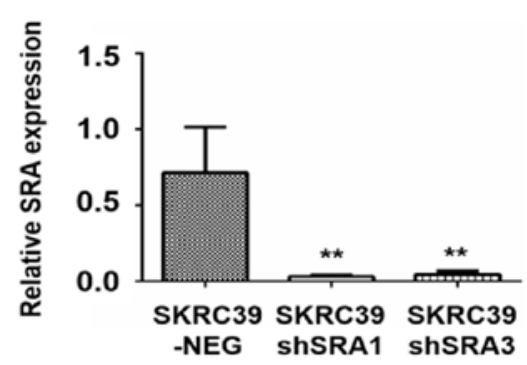

D
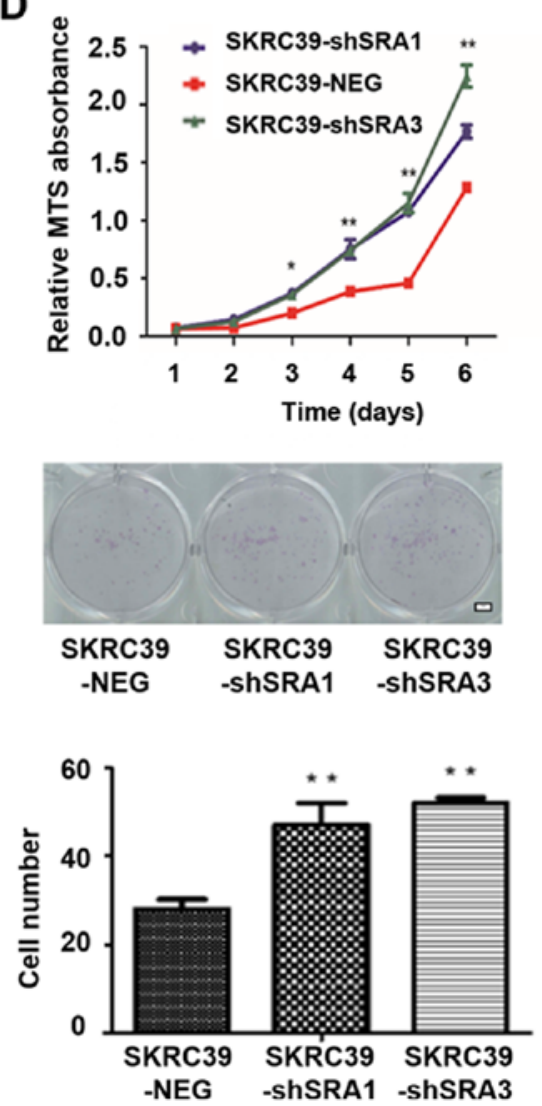

Figure 2. SRA inhibits the proliferative ability of RCC cells. (A) A498 cell stably overexpressing SRA were constructed using the lentiviral system and confirmed by RT-qPCR assay. (B) Knockdown of SRA in SKRC39 cells was established using shRNA. (C and D) The proliferation and colony formation of A498-SRA cells and SKRC39-shRNA cells were examined by MTS assay and colony formation assay, respectively. Data represent the means \pm SD of 3 independent experiments. ${ }^{*} \mathrm{P}<0.05,{ }^{* *} \mathrm{P}<0.01,{ }^{* * *} \mathrm{P}<0.001$ vs. respective control. SRA, steroid receptor RNA coactivator; RCC, renal cell carcinoma.

identify stem-like cells in tumorigenesis of RCC (25). Herein, flow cytometric analysis was performed to detect the percentages of $\mathrm{CD} 44^{+} / \mathrm{CD} 24-$ cells in the A498-SRA cells and SKRC39-shSRA cells. As shown in Fig. 5A, 
A

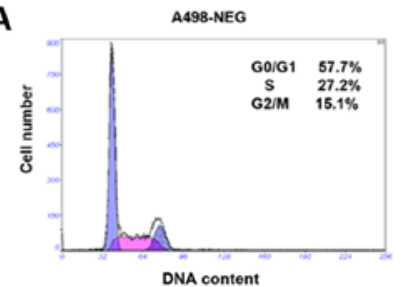

B

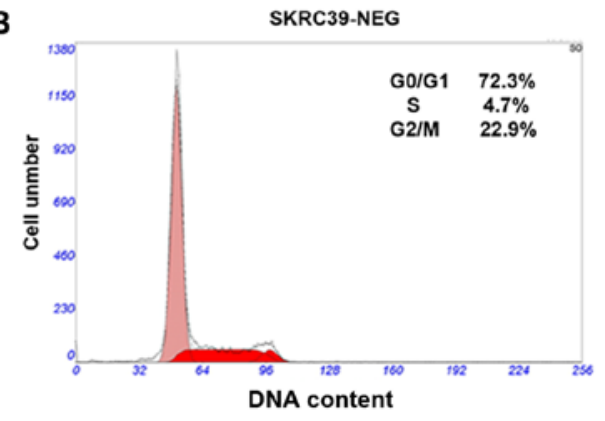

SKRC39-shSRA3

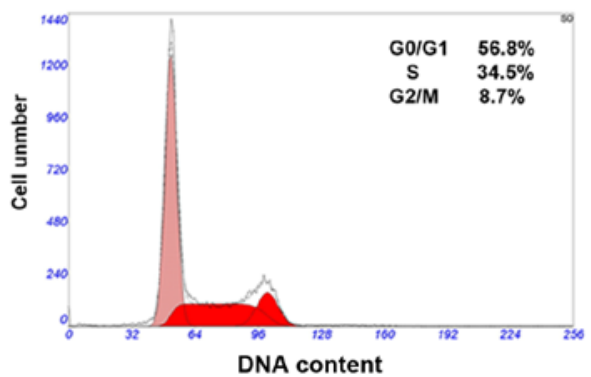

C

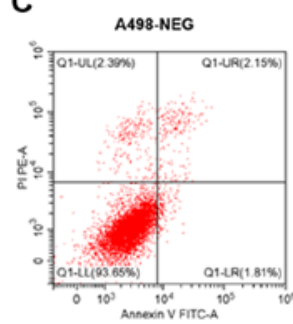

D SKRC39-NEG

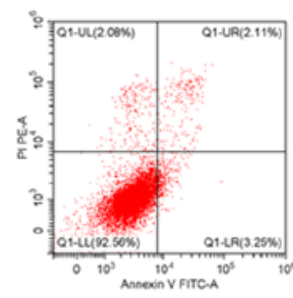

E

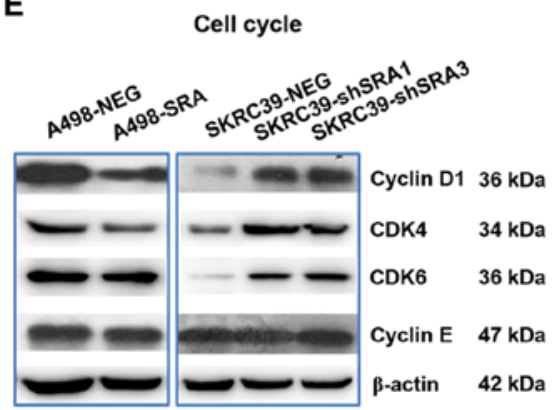

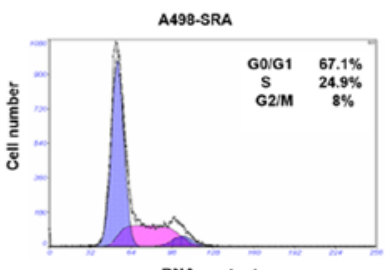

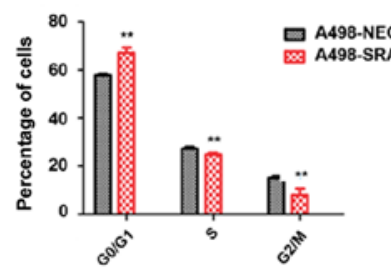

SKRC39-ShSRA1
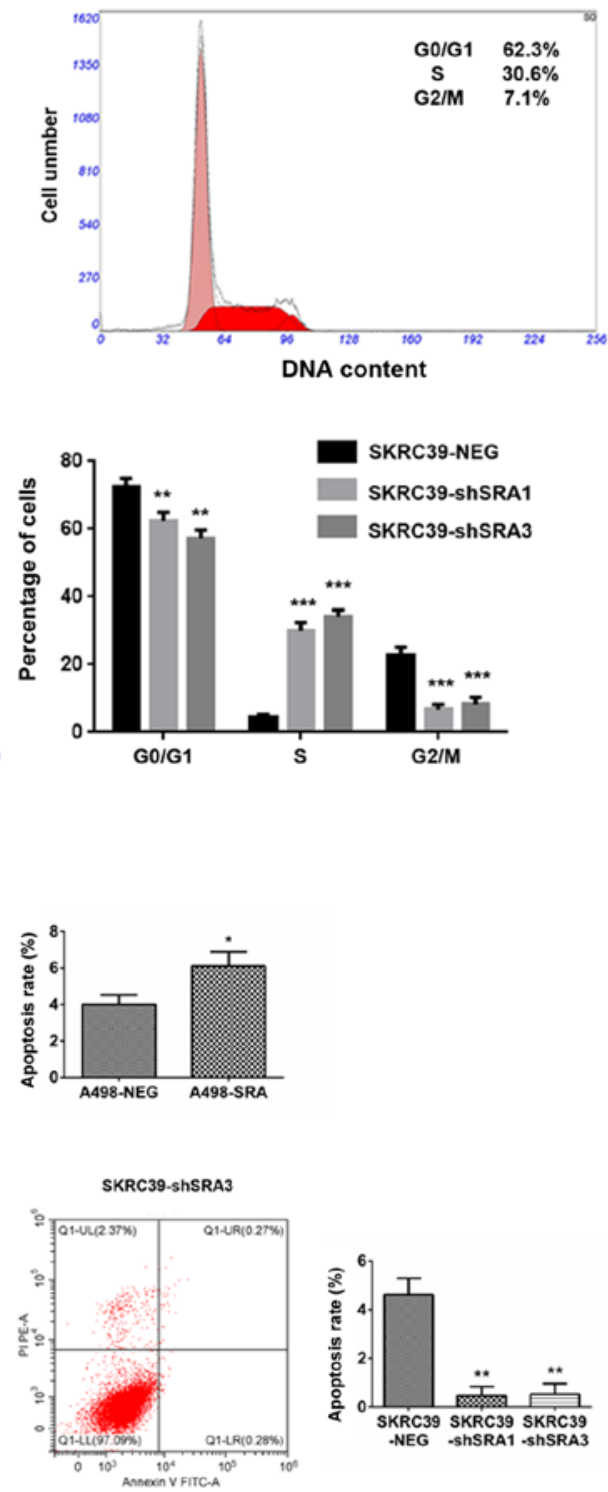

$\mathbf{F}$

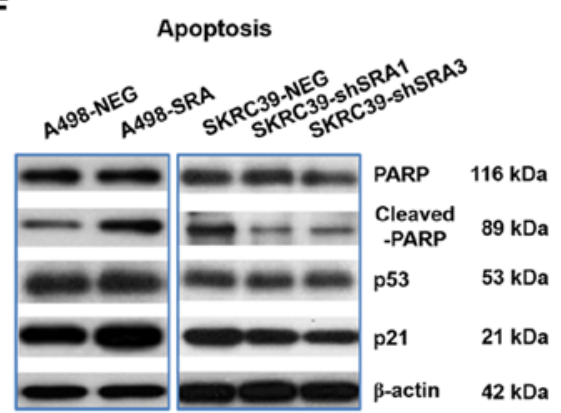

Figure 3. SRA inhibits the cell cycle and promotes apoptosis of RCC cells. (A and B) Flow cytometry was used to analyze the cell cycle of A498-SRA cells and SKRC39-shRNA cells. (C and D) The apoptosis of A498-SRA cells and SKRC39-shRNA cells was measured by staining with Annexin V/PI, followed by FACS analysis. (E) The expression levels of cyclin D1, CDK4, CDK-6 and cyclin E were detected by western blot analysis both in A498-SRA cells and SKRC39-shRNA cells. (F) Western blot analysis indicated the protein expression levels of PARP, cleaved PARP, p21 and p53 in A498-SRA cells and SKRC39-shRNA cells. Data represent the means $\pm \mathrm{SD}$ of 3 independent experiments. ${ }^{*} \mathrm{P}<0.05,{ }^{* * *} \mathrm{P}<0.01,{ }^{* * *} \mathrm{P}<0.001$ vs. respective control. SRA, steroid receptor RNA coactivator. 
A
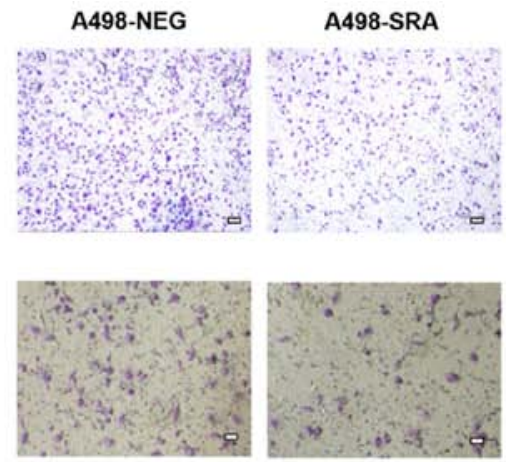
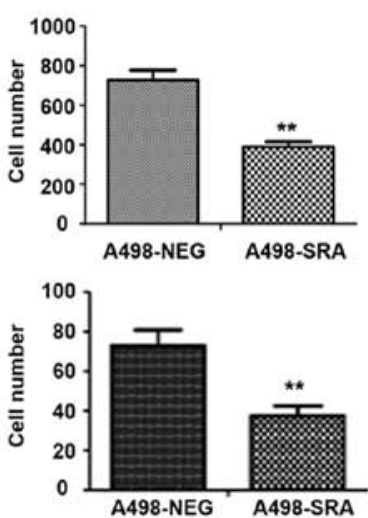

B
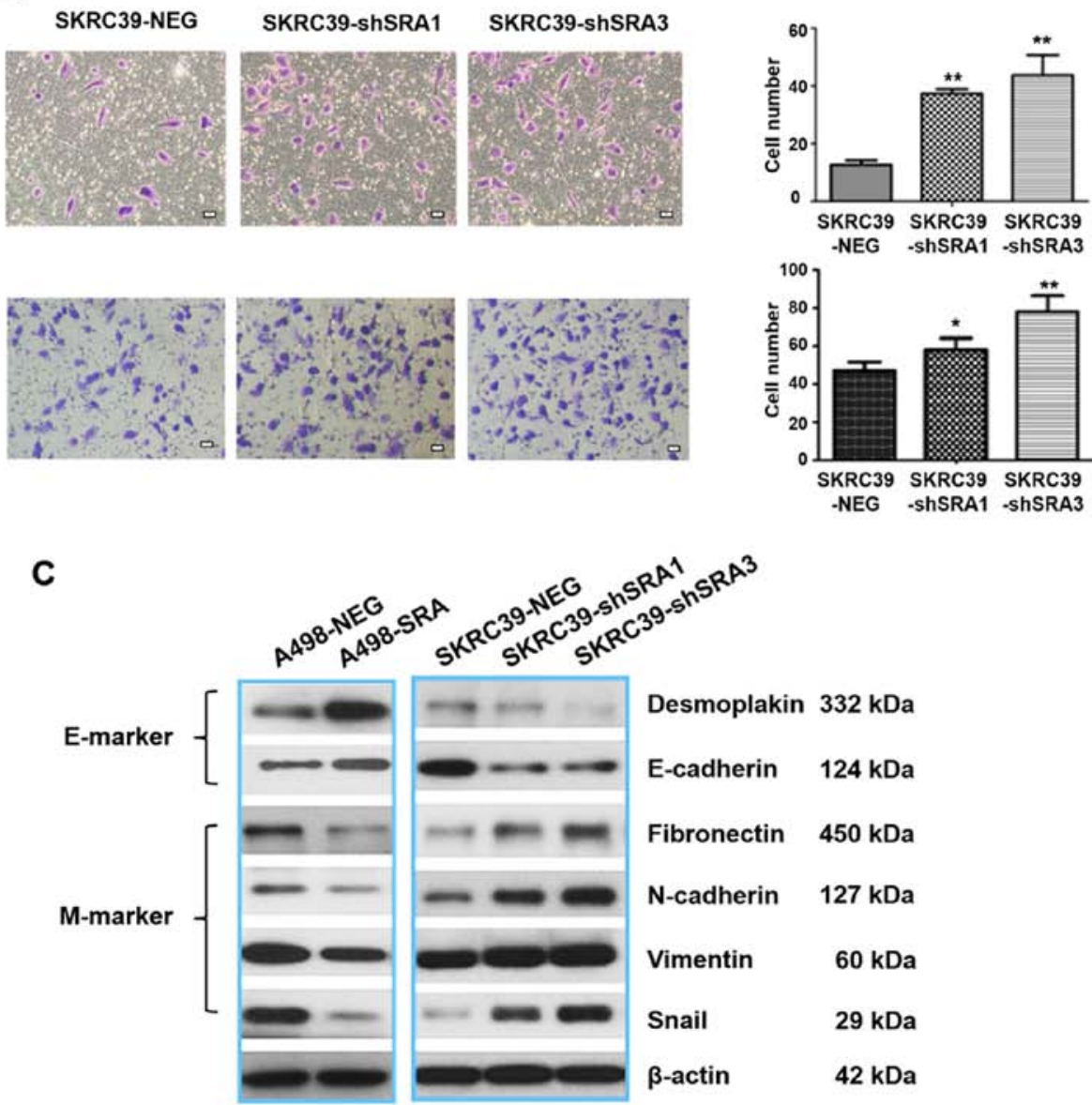

Figure 4. SRA inhibits the migration and invasion of RCC cells. (A and B) Transwell assay was used to measure the migration and invasion of A498-SRA cells and SKRC39-shRNA cells. Representative micrographs (left panels) and quantification (right panels) of crystal violet-stained cells from 3 independent experiments. (C) Western blot analysis was performed to detect the EMT markers (desmoplakin, E-cadherin, fibronectin, N-cadherin, vimentin and Snail) in A498-SRA and SKRC39-shSRA cells. Data represent the means \pm SD of 3 independent experiments. ${ }^{*} \mathrm{P}<0.05$, ${ }^{* *} \mathrm{P}<0.01$ vs. respective control. SRA, steroid receptor RNA coactivator.

the overexpression of SRA significantly decreased the percentage of $\mathrm{CD}_{4} 4^{+} / \mathrm{CD} 24^{-}$in the A498 cells (Fig. 5A), while the knockdown of SRA in the SKRC39 cells exerted an opposite effect (Fig. 5B). As previously reported, sphere-forming assays can reflect the ability of cellular self-renewal and proliferation, resulting in the acquisition of stem cell properties (26). The present study found that the overexpression of SRA reduced the sphere-forming efficiency of A498 cells (Fig. 5C), while the knockdown of SRA induced SKRC39 cell to form spheres (Fig. 5D). These findings were consistent with those of previous studies (27-30) and the present data, demonstrating that SRA decreased the expression levels of the stemness markers, CD44, sex determining region Y-box 2 (SOX-2), ATP-binding cassette transporter $\mathrm{G} 2$ (ABCG2) and octamer-binding transcription factor 4(OCT-4) (Fig. 5E). The above-mentioned results suggested that SRA regulated the stem-like characteristics of RCC cells.

The ERK signaling pathway is not required for the inhibition of the proliferation, migration and invasion of RCC cells by $S R A$. To further investigate the preliminary mechanisms of 

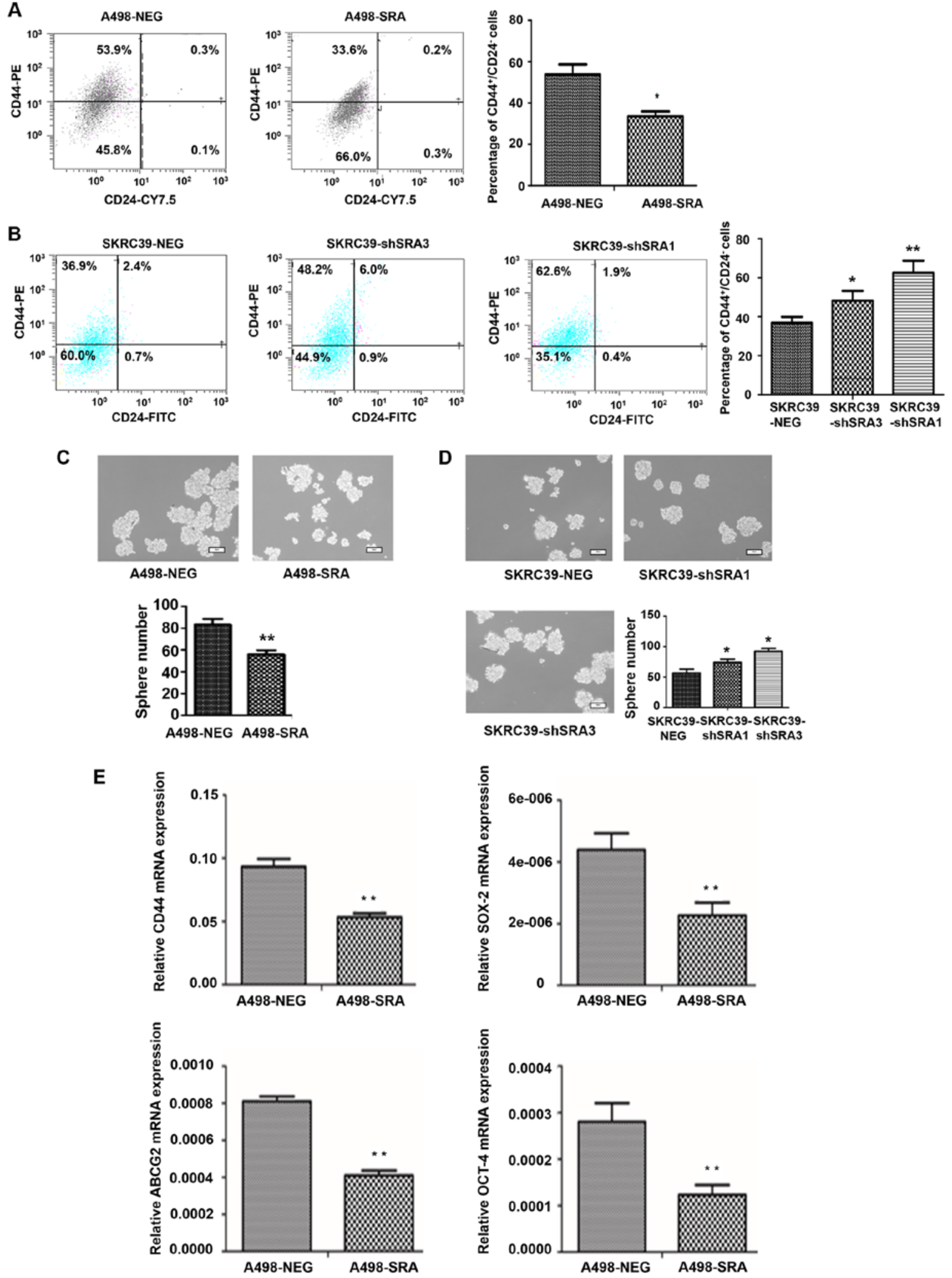

Figure 5. SRA downregulates stem-like cell markers in RCC cells. (A and B) The percentages of CD44 $/ \mathrm{CD} 24$ cells were detected by flow cytometric analysis in A498-SRA cells and SKRC39-shSRA cells, respectively. (C and D) The sphere formation ability of A498-SRA cells and SKRC39-shSRA cells were measured by sphere formation assay. (E) The expression levels of CD44, SOX-2, ABCG2 and OCT-4 in A498-SRA cells and SKRC39-shSRA were detected by RT-qPCR assay. Data represent the means \pm SD of 3 independent experiments. ${ }^{*} \mathrm{P}<0.05,{ }^{* *} \mathrm{P}<0.01$, vs. respective control. SRA, steroid receptor RNA coactivator; RCC, renal cell carcinoma.

EMT regulated by SRA in RCC cells, the effects of SRA on several classical signaling pathways, including the ERK, JNK and STAT3 pathways were detected. Among these signaling pathways, it was found that the overexpression of SRA significantly upregulated the levels of phospho-ERK1/2 in the A498 cells, while the knockdown of SRA markedly inhibited ERK1/2 

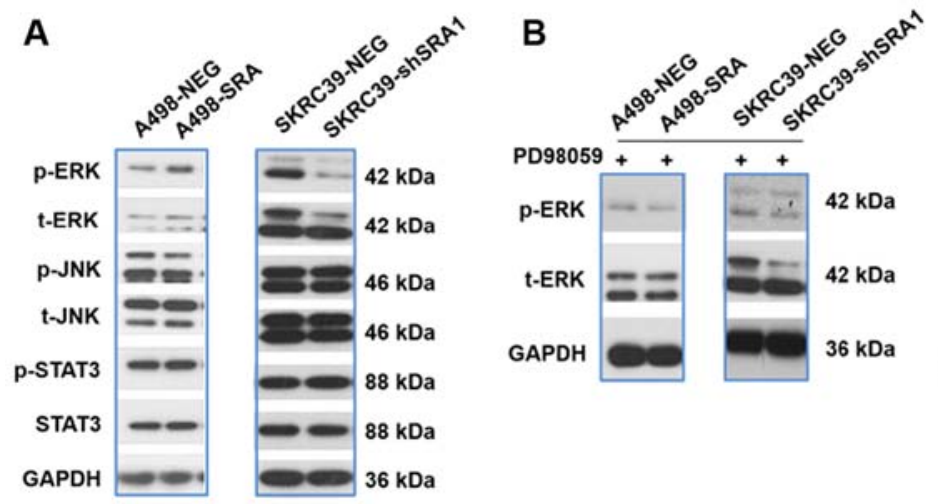

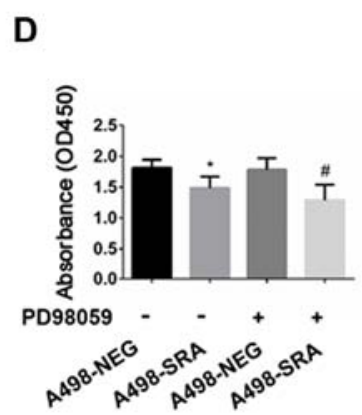

E
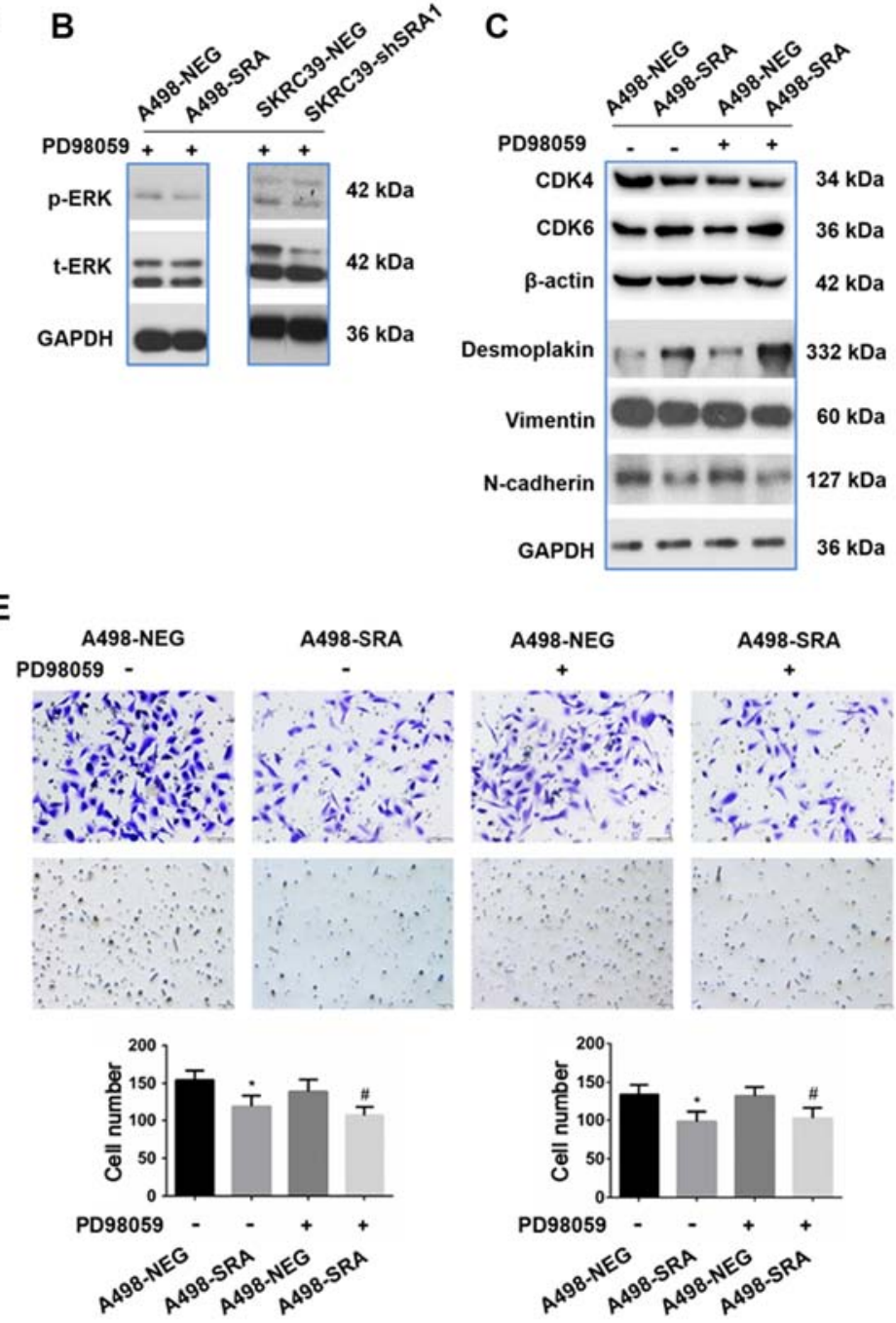

Figure 6. SRA-induced phosphorylation of ERK is dispensable for EMT in RCC cells. (A) The related proteins of ERK, JNK and STAT3 pathways were detected by western blot analysis. (B) The expression levels of p-ERK1/2 and total ERK1/2 were measured by western blot analysis with the ERK1/2 inhibitor, PD98059. (C) The levels of proliferation-related markers (CDK4 and CDK6) and EMT-related markers (desmoplakin, E-cadherin, N-cadherin) were measured by western blot analysis in A498-SRA cells and SKRC39-shSRA cells pre-treated with the ERK1/2 inhibitor. (D) Cell proliferation was measured by CCK-8 proliferation assay. (E) Transwell assay was performed to evaluate the effects of SRA and PD98059 on RCC migration and invasion. Data represent the means \pm SD of 3 independent experiments. ${ }^{*} \mathrm{P}<0.05$, compared to A498-NEG cells; ${ }^{*} \mathrm{P}<0.05$, compared to A498-NEG cells treated with PD98059. SRA, steroid receptor RNA coactivator; RCC, renal cell carcinoma.

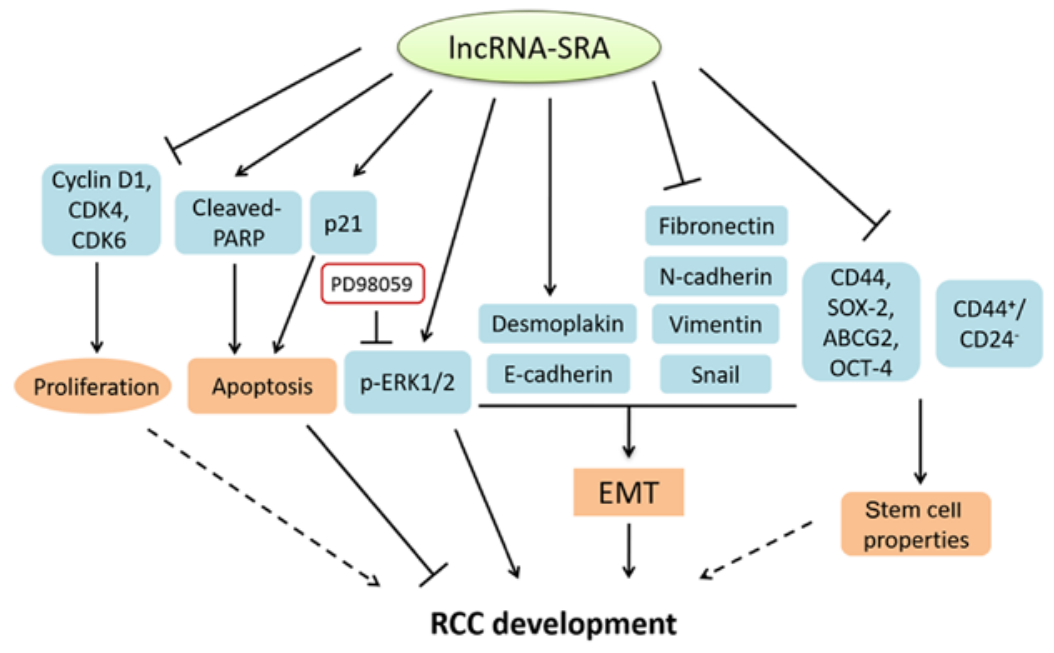

Figure 7. Schematic model summarizing the effects and signaling pathway of SRA in RCC. SRA exhibited a significant role in inhibiting cell motility of RCC through reducing the cell proliferation, promoting apoptosis, suppressing EMT and stemness characteristics, which is potentially independently of ERK signaling pathway. SRA, steroid receptor RNA coactivator; RCC, renal cell carcinoma. 
phosphorylation in the SKRC39 cells (Fig. 6A). Furthermore, the ERK inhibitor, PD98059, abolished ERK1/2 phosphorylation in both the A498-SRA and SKRC39-shRNA cells (Fig. 6B). The potential role of ERK in proliferation and EMT markers was also investigated in the A498-SRA cells and SKRC39-shRNA cells. As shown in Fig. 6C, the abrogation of the ERK1/2 pathway did not affect the expression levels of proliferation- and EMT-related markers mediated by SRA. Although SRA attenuated the abilities of proliferation, migration and invasion, PD98059 exerted no obvious effects on A498-NEG cells or A498-SRA cells compared with the untreated A498-NEG cells or A498-SR A cells (Fig. 6D and E).

The above-mentioned results indicated that SRA inhibited the cell proliferation, promoted apoptosis, suppressed EMT and stemness characteristics, while ERK signaling pathway was dispensable for the roles of SRA in RCC progression (Fig. 7).

\section{Discussion}

RCC is the most common type of urological malignancy. The incidence of RCC has been increasing over the past two decades (3). The lack of effective biomarkers and therapies has led to a high human morbidity (31). It is worth noting that among all hallmarks of cancer, sustaining proliferative signaling, activating migration and invasion, and gaining stem cell characteristics are most important factors responsible for systemic spreading and treatment resistance (32).

SRA was initially identified in 1999 and functions to increase the activity of steroid receptors (33). Although a number of studies on the structure and molecular functions of SRA are emerging, the physiological roles of SRA have not yet been fully elucidated. The present study found SRA was downregulated in both RCC clinical samples and cell lines. SRA inhibited the proliferation, migration, invasion and stemness of RCC cells via suppressing the cell cycle, intervening the EMT process and altering stemness markers, which indicated a potential tumor suppressive role of SRA in RCC. However, in contrast to the findings of the present study, several studies have defined SRA as an oncogene, since it is overexpressed in ovarian and breast cancers $(34,35)$. It was therefore considered that SRA may exhibit a tissue-specific expression pattern and function as an oncogene or tumor suppressor in different types of cancers. Moreover, intracellular signaling pathways, the tumor microenvironment, as well as energy metabolism in different cancer types are also closely related to the functions of SRA. For example, Lanz et al demonstrated that the overexpression of SRA exhibited potent promoting activities on cellular proliferation and differentiation via the aberrant stimulation of ER activity in breast cancer (9). SRA plays an anticancer role in osteosarcoma by sponging miR-208a, as it reduces cell migration, invasion and proliferation, while it promotes cell apoptosis (36). In the present study, the expression levels of SRA were found to be significantly downregulated in RCC tissues in comparison with the matched normal tissues. The overexpression of SRA inhibited the proliferation, colony formation, migration, invasion and stemness of RCC cells. Conversely, the knockdown of SRA markedly promoted cell growth and the aggressive behaviors in vitro. These findings revealed that SRA played a beneficial role in suppressing RCC proliferation and cell motility.
RCC cells are shown to have an intermediate EMT phenotype with low levels of desmoplakin and E-cadherin, and mesenchymal features, such as fibronectin, $\mathrm{N}$-cadherin, vimentin and Snail $(37,38)$. As was expected, the findings of the present study demonstrated that SRA significantly increased the expression levels of epithelial-specific markers and decreased the expression levels of mesenchymal-associated regulators. The loss of E-cadherin is considered to be a crucial event in EMT, whereas $\mathrm{N}$-cadherin promotes trans-endothelial migration, which subsequently leads to a diminished in intercellular adhesion, and ultimately triggers cancer invasion and migration. The EMT status renders make cells more prone to exhibit cancer stem cell-like properties (39). As regards the existence of cancer stem cells, accumulating evidence has been indicated that stem-like cells are contributed to cancer initiation and progression (40). Similarly, the present study demonstrated that SRA reduced the percentage of CD44 ${ }^{+} / \mathrm{CD} 24^{-}$cells, which was associated with increased stem-like characteristics and a poor prognosis for patients with RCC. Consistently, SRA inhibited the self-renewal capability and reduced the expression levels of SOX-2, CD44, ABCG2 and OCT-4, which play important roles in maintaining cancer cell stemness $(41,42)$. Herein, SRA promoted RCC progression by regulating EMT markers, stemness properties and stem cell-like protein expressions.

Considering the crucial roles of several signaling pathways, such as ERK, JNK and STAT pathway in cancer progression (43-45), the present study investigated the alterations of the above-mentioned pathways in RCC cells. The results revealed that SRA markedly activated the ERK signaling pathway. However, the inhibition of the ERK pathway with PD98059 had minimal effects on proliferation, migration and invasion inhibited by SRA. Therefore, the specific role of the ERK pathway on proliferation and invasion inhibited by SRA warrant further investigation. During RCC progression mediated by SRA, ERK phosphorylation may lead to the proteasome-dependent degradation of multiple phosphoproteins required for cell proliferation and invasion. IncRNA sequences convey functions by binding to DNA or protein. In a previous study, it was found that SRA induced the upregulation of phospho-cAMP response element binding protein (p-CREB) expression via the MEK-ERK signaling pathway in vascular smooth muscle cell proliferation (46). Thus, CREB may be a direct interacting molecule of SRA in the proliferation and stemness of RCC cells. As a ubiquitous transcription factor, CREB carries out its role by binding to the promoter containing a CRE motif. The molecular mechanisms of SRA in regulating the promoter containing CRE motif warrant further investigation.

In conclusion, the findings of the present study demonstrated the inhibitory effects of SRA on RCC proliferation, migration and invasion through the regulation of the cell cycle, EMT and stemness characteristics, which are potentially independent of the ERK signaling pathway (Fig. 7). Therefore, determining the protective functions of SRA may provide a promising therapeutic target for the diagnosis and therapy of RCC.

\section{Acknowledgements}

The authors would like to express their sincere gratitude to Professor Chao-Nan Qian of the SYSUCC Cancer Center for 
his support. The authors would also like to thank the SYSUCC Cancer Center for providing kind assistance. In addition, the authors are grateful to Dr Yajing Liu of the University of Michigan for her kind revision of the article.

\section{Funding}

The present study was supported by grants from the National Natural Sciences Foundation of China to LQ (nos. 81973668, 81774130, 81270359 and 81000946), the National Natural Sciences Foundation of China to DL (no. 81670268), the National Science Fund of Hunan Province for Distinguished Young Scholars to LQ (no. 2018JJ1018), the Open Funds of State Key Laboratory of Oncology in South China to LQ (no. HN2019-07) and the First-Class Discipline of Pharmaceutical Science of Hunan.

\section{Availability of data and materials}

The datasets used and/or analyzed during the current study are available from the corresponding author on reasonable request.

\section{Authors' contributions}

LQ conceived and designed the study. CJZ, NZ and CL analyzed the data and wrote the manuscript. YTY performed the experiments. HTW provided the clinical samples. YS and DL interpreted the data for the study. All authors read and approved the final manuscript.

\section{Ethics approval and consent to participate}

All procedures performed in studies involving human participants were in accordance with the ethical standards of the institutional and national research committee and with the 1964 Helsinki Declaration and its later amendments or comparable ethical standards. The study was approved by the Committee for Ethical Review of Hunan University of Chinese Medicine. Informed consent was obtained prior to patient enrollment.

\section{Patient consent for publication}

Not applicable.

\section{Competing interests}

All authors declare that they have no competing interests.

\section{References}

1. Koul H, Huh JS, Rove KO, Crompton L, Koul S, Meacham RB and Kim FJ: Molecular aspects of renal cell carcinoma: A review. Am J Cancer Res 1: 240-254, 2011.

2. Ferlay J, Steliarova-Foucher E, Lortet-Tieulent J, Rosso S, Coebergh JW, Comber H, Forman D and Bray F: Cancer incidence and mortality patterns in Europe: Estimates for 40 countries in 2012. Eur J Cancer 49: 1374-1403, 2013.

3. Siegel RL, Miller KD and Jemal A: Cancer statistics, 2017. CA Cancer J Clin 67: 7-30, 2017.

4. Unverzagt S, Moldenhauer I, Nothacker M, Roßmeiß1 D, Hadjinicolaou AV, Peinemann F, Greco F and Seliger B: Immunotherapy for metastatic renal cell carcinoma. Cochrane Database Syst Rev 5: Cd011673, 2017.
5. Siegel RL, Miller KD and Jemal A: Cancer statistics, 2015. CA Cancer J Clin 65: 5-29, 2015.

6. Ridge CA, Pua BB and Madoff DC: Epidemiology and staging of renal cell carcinoma. Semin Intervent Radiol 31: 3-8, 2014

7. Murphy LC, Simon SL, Parkes A, Leygue E, Dotzlaw H, Snell L, Troup S, Adeyinka A and Watson PH: Altered expression of estrogen receptor coregulators during human breast tumorigenesis. Cancer Res 60: 6266-6271, 2000.

8. Liu C, Wu HT, Zhu N, Shi YN, Liu Z, Ao BX, Liao DF, Zheng XL and Qin L: Steroid receptor RNA activator: Biologic function and role in disease. Clin Chim Acta 459: 137-146, 2016.

9. Lanz RB, Chua SS, Barron N, Soder BM, DeMayo F and O'Malley BW: Steroid receptor RNA activator stimulates proliferation as well as apoptosis in vivo. Mol Cell Biol 23: 7163-7176, 2003.

10. Yan Y, Skliris GP, Penner C, Chooniedass-Kothari S, Cooper C, Nugent Z, Blanchard A, Watson PH, Myal Y, Murphy LC and Leygue E: Steroid Receptor RNA Activator Protein (SRAP): A potential new prognostic marker for estrogen receptor-positive/node-negative/younger breast cancer patients. Breast Cancer Res 11: R67, 2009.

11. Eoh KJ, Paek J, Kim SW, Kim HJ, Lee HY, Lee SK and Kim YT: Long non-coding RNA, steroid receptor RNA activator (SRA), induces tumor proliferation and invasion through the NOTCH pathway in cervical cancer cell lines. Oncol Rep 38: 3481-3488, 2017.

12. Bennett NC, Rajandram R, Ng KL and Gobe GC: Evaluation of steroid hormones and their receptors in development and progression of renal cell carcinoma. J Kidney Cancer VHL 1: 17-25, 2014.

13. Langner C, Ratschek M, Rehak P, Schips L and Zigeuner R: Steroid hormone receptor expression in renal cell carcinoma: An immunohistochemical analysis of 182 tumors. J Urol 171: 611-614, 2004.

14. Czarnecka AM, Niedzwiedzka M, Porta C and Szczylik C: Hormone signaling pathways as treatment targets in renal cell cancer (Review). Int J Oncol 48: 2221-2235, 2016.

15. Qin L, Zhang X, Zhang L, Feng Y, Weng GX, Li MZ, Kong QL, Qian CN, Zeng YX, Zeng MS, et al: Downregulation of BMI-1 enhances 5-fluorouracil-induced apoptosis in nasopharyngeal carcinoma cells. Biochem Biophys Res Commun 371: 531-535, 2008.

16. Livak KJ and Schmittgen TD: Analysis of relative gene expression data using real-time quantitative PCR and the 2(-Delta Delta C(T)) method. Methods 25: 402-408, 2001.

17. Qin L, Yang YB, Yang YX, Gong YZ, Li XL, Li GY, Luo HD, Xie XJ, Zheng XL and Liao DF: Inhibition of smooth muscle cell proliferation by ezetimibe via the cyclin D1-MAPK pathway. J Pharmacol Sci 125: 283-291, 2014.

18. Deng M, Zeng C, Lu X, He X, Zhang R, Qiu Q, Zheng G, Jia X, Liu H and He Z: miR-218 suppresses gastric cancer cell cycle progression through the CDK6/Cyclin D1/E2F1 axis in a feedback loop. Cancer Lett 403: 175-185, 2017.

19. Darzynkiewicz Z, Zhao H, Zhang S, Lee MY, Lee EY and Zhang Z: Initiation and termination of DNA replication during $S$ phase in relation to cyclins D1, E and A, p21WAF1, Cdt1 and the p12 subunit of DNA polymerase delta revealed in individual cells by cytometry. Oncotarget 6: 11735-11750, 2015.

20. Shamanna RA, Hoque M, Pe'ery T and Mathews MB: Induction of p53, p21 and apoptosis by silencing the NF90/NF45 complex in human papilloma virus-transformed cervical carcinoma cells. Oncogene 32: 5176-5185, 2013.

21. Micalizzi DS, Haber DA and Maheswaran S: Cancer metastasis through the prism of epithelial-to-mesenchymal transition in circulating tumor cells. Mol Oncol 11: 770-780, 2017.

22. Zhou P, Li B, Liu F, Zhang M, Wang Q, Liu Y, Yao Y and Li D: The epithelial to mesenchymal transition (EMT) and cancer stem cells: Implication for treatment resistance in pancreatic cancer. Mol Cancer 16: 52, 2017.

23. Thaper D, Vahid S, Nip KM, Moskalev I, Shan X, Frees S, Roberts ME, Ketola K, Harder KW, Gregory-Evans C, et al: Targeting Lyn regulates Snail family shuttling and inhibits metastasis. Oncogene 36: 3964-3975, 2017.

24. Yu CC, Lo WL, Chen YW, Huang PI, Hsu HS, Tseng LM, Hung SC, Kao SY, Chang CJ and Chiou SH: Bmi-1 regulates Snail expression and promotes metastasis ability in head and neck squamous cancer-derived ALDH1 positive cells. J Oncol 2011: 609259, 2011

25. Yuan ZX, Mo J, Zhao G, Shu G, Fu HL and Zhao W: Targeting strategies for renal cell carcinoma: From renal cancer cells to renal cancer stem cells. Front Pharmacol 7: 423, 2016. 
26. Xiao W, Gao Z, Duan Y, Yuan W and Ke Y: Notch signaling plays a crucial role in cancer stem-like cells maintaining stemness and mediating chemotaxis in renal cell carcinoma. J Exp Clin Cancer Res 36: 41, 2017.

27. Kim Y, Yeon M and Jeoung D: DDX53 regulates cancer stem cell-like properties by binding to SOX-2. Mol Cells 40: 322-330, 2017.

28. Hu J, Li J, Yue X, Wang J, Liu J, Sun L and Kong D: Expression of the cancer stem cell markers ABCG2 and OCT-4 in right-sided colon cancer predicts recurrence and poor outcomes. Oncotarget 8: 28463-28470, 2017.

29. Wang MC, Jiao M, Wu T, Jing L, Cui J, Guo H, Tian T, Ruan ZP, Wei YC, Jiang LL, et al: Polycomb complex protein BMI-1 promotes invasion and metastasis of pancreatic cancer stem cells by activating PI3K/AKT signaling, an ex vivo, in vitro, and in vivo study. Oncotarget 7: 9586-9599, 2016.

30. Senbanjo LT and Chellaiah MA: CD44: A multifunctional cell surface adhesion receptor is a regulator of progression and metastasis of cancer cells. Front Cell Dev Biol 5: 18, 2017.

31. Su D, Stamatakis L, Singer EA and Srinivasan R: Renal cell carcinoma: Molecular biology and targeted therapy. Curr Opin Oncol 26: 321-327, 2014.

32. Hanahan D and Weinberg RA: Hallmarks of cancer: The next generation. Cell 144: 646-674, 2011.

33. Lanz RB, McKenna NJ, Onate SA, Albrecht U, Wong J, Tsai SY, Tsai MJ and O'Malley BW: A steroid receptor coactivator, SRA, functions as an RNA and is present in an SRC-1 complex. Cell 97: 17-27, 1999

34. Cooper C, Guo J, Yan Y, Chooniedass-Kothari S, Hube F, Hamedani MK, Murphy LC, Myal Y and Leygue E: Increasing the relative expression of endogenous non-coding Steroid Receptor RNA Activator (SRA) in human breast cancer cells using modified oligonucleotides. Nucleic Acids Res 37: 4518-4531, 2009.

35. Lin K, Zhan H, Ma J, Xu K, Wu R, Zhou C and Lin J: Silencing of SRA1 regulates ER expression and attenuates the growth of stromal cells in ovarian endometriosis. Reprod Sci 24: 836-843, 2017.

36. Guo W, Jiang H, Li H, Li F, Yu Q, Liu Y, Jiang W and Zhang M: LncRNA-SRA1 suppresses osteosarcoma cell proliferation while promoting cell apoptosis. Technol Cancer Res Treat 18: $1533033819841438,2019$.
37. Son $\mathrm{H}$ and Moon A: Epithelial-mesenchymal transition and cell invasion. Toxicol Res 26: 245-252, 2010.

38. Lee JY and Kong G: Roles and epigenetic regulation of epithelial-mesenchymal transition and its transcription factors in cancer initiation and progression. Cell Mol Life Sci 73: 4643-4660, 2016.

39. Nieto MA, Huang RY, Jackson RA and Thiery JP: EMT: 2016. Cell 166: 21-45, 2016.

40. Cheng B, Yang G, Jiang R, Cheng Y, Yang H, Pei L and Qiu X: Cancer stem cell markers predict a poor prognosis in renal cell carcinoma: A meta-analysis. Oncotarget 7: 65862-65875, 2016.

41. Sabnis NG, Miller A, Titus MA and Huss WJ: The Efflux transporter ABCG2 maintains prostate stem cells. Mol Cancer Res 15: 128-140, 2017.

42. Qin L, Yin YT, Zheng FJ, Peng LX, Yang CF, Bao YN, Liang YY, Li XJ, Xiang YQ, Sun R, et al: WNT5A promotes stemness characteristics in nasopharyngeal carcinoma cells leading to metastasis and tumorigenesis. Oncotarget 6: 10239-10252, 2015.

43. Chiu LY, Hsin IL, Yang TY, Sung WW, Chi JY, Chang JT, Ko JL and Sheu GT: The ERK-ZEB1 pathway mediates epithelial-mesenchymal transition in pemetrexed resistant lung cancer cells with suppression by vinca alkaloids. Oncogene 36: 242-253, 2017.

44. Wang SY, Gao K, Deng DL, Cai JJ, Xiao ZY, He LQ, Jiao HL, Ye YP, Yang RW, Li TT, et al: TLE4 promotes colorectal cancer progression through activation of JNK/c-Jun signaling pathway. Oncotarget 7: 2878-2888, 2016.

45. Chuang CH, Greenside PG, Rogers ZN, Brady JJ, Yang D, Ma RK, Caswell DR, Chiou SH, Winters AF, Grüner BM, et al: Molecular definition of a metastatic lung cancer state reveals a targetable CD109-Janus kinase-Stat axis. Nat Med 23: 291-300, 2017.

46. Zhang CJ, Liu C, Wang YX, Zhu N, Hu ZY, Liao DF and Qin L: Long non-coding RNA-SRA promotes neointimal hyperplasia and vascular smooth muscle cells proliferation via MEK-ERK-CREB pathway. Vascul Pharmacol 116: 16-23, 2019.

This work is licensed under a Creative Commons Attribution-NonCommercial-NoDerivatives 4.0 International (CC BY-NC-ND 4.0) License. 